\title{
Effects of Hydrocortisone Combined with Vitamin C and Vitamin B1 Versus Hydrocortisone Alone on Microcirculation in Patients with Septic Shock: A Prospective, Double-Blind, Randomized, Controlled Trial
}

Jinlong Wang ( $\square$ doctorwang2016@163.com )

Southeast University https://orcid.org/0000-0002-7990-9852

Qianwen Song

Southeast University

Shuhe Yang

Southeast University

Haofei Wang

Southeast University

Shanshan Meng

Southeast University

Lili Huang

Southeast University

Qing Li

Southeast University

Jingyuan Xu

Southeast University

Jianfeng Xie

Southeast University

Yingzi Huang

Southeast University https://orcid.org/0000-0001-8304-3580

Research Article

Keywords: septic shock, hydrocortisone, vitamin, microcirculation

Posted Date: July 20th, 2021

DOI: https://doi.org/10.21203/rs.3.rs-705003/v1 
License: (c) (i) This work is licensed under a Creative Commons Attribution 4.0 International License. Read Full License 


\section{Abstract}

Background: Hydrocortisone combined with vitamin C and vitamin B1 is a promising treatment for septic shock. This study aimed to investigate the effects of hydrocortisone combined with vitamin $\mathrm{C}$ and vitamin B1 versus hydrocortisone alone on microcirculation in patients with septic shock.

Methods: This prospective, double-blind, randomized, controlled trial enrolled septic shock patients admitted to the intensive care unit of a tertiary teaching hospital from February 1, 2019, to January 1 , 2020. We randomly assigned the enrolled patients to the treatment group (hydrocortisone combined with vitamin C and vitamin B1 added to standard care) and control group (hydrocortisone alone added to standard care) in a 1:1 ratio. The primary outcome was the perfusion vascular density (PVD) 24 hours after treatment. We used the sublingual microcirculation imaging system to monitor the PVD. We further validated the primary outcome by observing differences in renal perfusion monitored by renal contrastenhanced ultrasound between the treatment and control groups.

Results: Twelve patients in the treatment group and ten in the control group completed the study. The baseline characteristics and hemodynamic parameters were comparable between the groups. No statistically significant difference was found in the PVD between the treatment and control groups at baseline. The PVD in the treatment group was significantly higher than that in the control group at 4 hours after treatment (mean difference, 7.042; 95\% Cl, 2.227-11.857; $\mathrm{P}=0.009$ ) and 24 hours after treatment (mean difference, $7.075 ; 95 \% \mathrm{Cl}, 2.390-11.759 ; \mathrm{P}=0.008$ ). The sublingual microcirculation parameters (proportion of perfusion vessels, total vascular density, microvascular flow index) and renal perfusion parameters (peak intensity, regional blood flow) in the treatment group were significantly better than those in the control group at 24 hours after treatment.

Conclusions: Compared with hydrocortisone alone, hydrocortisone combined with vitamin $\mathrm{C}$ and vitamin B1 significantly improves microcirculation in patients with septic shock. The findings are further supported by improved renal perfusion in the treatment group.

Trial registration: Protocol Registration and Results System, NCT03821714. Registered 19 January 2019, https://register.clinicaltrials.gov

\section{Background}

Sepsis is a life-threatening organ dysfunction caused by a dysregulated host response to infection. Septic shock is a subset of sepsis and leads to high mortality. Globally, approximately 48 million incident cases of sepsis and 11 million sepsis-related deaths (accounting for approximately $20 \%$ of all deaths) occur annually [1]. A national multicenter epidemiological investigation in China showed that the 90-day mortality of patients with septic shock was more than $50 \%$ [2]. Effectively reducing mortality and improving the prognosis in patients with sepsis and septic shock is a crucial task for critical care medicine. 
Hydrocortisone combined with vitamin C and vitamin B1 (combination therapy) is a promising treatment for septic shock. Marik and colleagues explored the effect of the combination therapy on mortality in patients with septic shock for the first time, revealing that the combination therapy significantly reduces the in-hospital mortality, sequential organ failure assessment (SOFA) score, and duration of vasopressor use [3]. However, this study has some shortcomings, such as the small sample size and before-after study design. Since the publication of this study, the use of combination therapy has increased gradually [4], and numerous studies have begun to explore the effect of combination therapy on the prognosis of septic shock patients [5-14]. But these studies have produced inconsistent results and a lack of mechanistic research.

Endothelial and microcirculation dysfunction play key roles in the occurrence and development of septic shock. Theoretically, the combination therapy could protect endothelial function and microcirculation in many ways [15]. Additionally, hydrocortisone and vitamin $C$ have a synergistic effect on endothelial protection [16]. This study aimed to observe the effects of the combination therapy versus hydrocortisone alone on microcirculation in septic shock patients.

\section{Methods}

\section{Study design}

This prospective, double-blind, randomized controlled trial aimed to evaluate the effects of hydrocortisone combined with vitamin $\mathrm{C}$ and vitamin $\mathrm{B} 1$ versus hydrocortisone alone on the perfusion vascular density (PVD) in patients with septic shock. We randomly assigned the enrolled patients to the treatment group (hydrocortisone combined with vitamin $\mathrm{C}$ and vitamin B1 therapy added to standard care) and control group (hydrocortisone alone added to standard care) in a 1:1 ratio. The Clinical Research Ethics Committee of the Zhongda Hospital affiliated with Southeast University approved this study (2018ZDSYLL057-P01), and all participants signed informed consent forms. The clinical trial protocol was registered at clinicaltrial.gov (NCT03821714).

\section{Participants}

From February 1, 2019, to January 1, 2020, we enrolled patients with septic shock admitted to the intensive care unit (ICU) of the tertiary teaching hospital. All newly admitted patients were screened four times on the first day of ICU admission to determine whether they met the study's inclusion criteria and ensure early enrollment. Because of the difficulty of screening late at night, the screening time points were 7:00, 13:00, 19:00, and 23:00. The main inclusion criteria were septic shock patients with norepinephrine doses $\geq 15 \mu \mathrm{g} / \mathrm{min}$. According to the requirements of the ethics committee, the included patients were aged at least 18 years and had a maximum age of 80 years. The exclusion criteria included the following: uncontrolled malignancy; clinicians judging that glucocorticoid therapy should not be used; glucocorticoid therapy being used within seven days before admission; patients meeting the inclusion 
criteria for more than 12 hours; patients refusing to sign the informed consent form; patients expected to die within 24 hours. Sepsis was defined as an acute change in the total SOFA score $\geq 2$ points consequent to infection. Septic shock was defined as sepsis with persisting hypotension requiring vasopressors to maintain a mean arterial pressure (MAP) $\geq 65 \mathrm{mmHg}$ despite adequate volume resuscitation [17]. Additional file 1 shows the sample size calculation method.

\section{Randomization And Blinding}

We randomly assigned the enrolled patients to the treatment and control groups in a 1:1 ratio. We used a 1-100 random number table for simple randomized assignments. If the random number was odd, the patient was assigned to the treatment group; otherwise, the patient was assigned to the control group. Patients were numbered according to their enrollment order, and the random results of each patient were concealed by the envelope method. Screening researchers opened the envelope based on the patient's enrollment number and then informed the treating nurse of the treatment plan. Finally, the treating nurse completed the medication according to the prescribed usage. Participants and microcirculation evaluators were blinded to the grouping scheme.

\section{Intervention}

The treatment group was treated with hydrocortisone combined with vitamin $\mathrm{C}$ and vitamin $\mathrm{B} 1$ added to standard care. Hydrocortisone $(200 \mathrm{mg}$ ) was continuously pumped intravenously for 24 hours. Vitamin C $(1.5 \mathrm{~g})$ was dissolved in $100 \mathrm{ml}$ of normal saline and infused intravenously. The infusion time was 30-60 min, and the interval was 6 hours; 4 doses were used. Vitamin B1 $(200 \mathrm{mg})$ was dissolved in $50 \mathrm{ml}$ of normal saline and infused intravenously. The infusion time was 30-60 min, and the interval was 12 hours; 2 doses were used. The control group was treated with hydrocortisone alone added to standard care. The use of hydrocortisone was the same as that in the treatment group. Additionally, the same amount of saline as the treatment group was used as a control. Standard care was performed according to the international guidelines for the management of sepsis and septic shock, such as infection source control, fluid resuscitation, norepinephrine use, and antimicrobial use [18].

\section{Outcome}

The primary outcome was the PVD at 24 hours after treatment. We used a sublingual microcirculation imaging system to monitor the PVD at baseline, 4 hours and 24 hours after treatment. The secondary outcomes included other sublingual microcirculation parameters at 24 hours after treatment (proportion of perfusion vessels [PPV], total vascular density [TVD], and microvascular flow index [MFI]). To further support the primary outcome, we performed renal contrast-enhanced ultrasound (CEUS) at baseline and 24 hours after treatment to observe the differences in renal perfusion between the treatment and control groups. Other secondary outcomes were renal CEUS parameters at 24 hours after treatment (peak 
intensity [PI], regional blood flow [RBF], regional blood volume [RBV], time to peak [TTP], mean transfer time [MTT]); lactate level at 24 hours after treatment; norepinephrine dose; ICU stay; total hospital stay; and 28-day mortality. The methods to monitor sublingual microcirculation and renal CEUS are shown in Additional file 2 and Additional file 3.

\section{Statistical analysis}

Continuous variables were shown as the mean (standard deviation) or median (interquartile range) according to the data distribution. Categorical variables were shown as numbers and percentages.

For repeated measurement data (measurement number $\geq 3$ ), we used two-way repeated-measures ANOVA to compare differences between the treatment and control groups. If Mauchly's test of sphericity was not satisfied, we used the Greenhouse-Geisser method for correction. To compare multiple data sets (number $\geq 3$ ), we used the Bonferroni method to correct $P$ values. For data measured before and after treatment, we used baseline data as covariates and used covariance analysis to compare posttreatment differences between the treatment and control groups. We used either the independent samples t-test or Mann-Whitney $U$ test for continuous variables to compare the baseline characteristics of patients in the treatment and control groups and Fisher's exact test for categorical variables. Two-sided $p$ values less than 0.05 were considered statistically significant. Statistical analysis was performed using SPSS (Version 23.0; IBM Corp.) and R (Version 3.6.3; R Project for Statistical Computing).

\section{Results}

\section{Participants}

We screened 108 patients with septic shock. Among them, 27 patients were randomized after excluding 81 patients. The main reasons for exclusions were as follows: a norepinephrine dose less than 15 $\mu \mathrm{g} / \mathrm{min}$, age older than 80 years, malignancy, and clinicians judging that hydrocortisone should not be used. Among the randomized patients, 15 were allocated to the treatment group, and 12 to the control group. All the randomized patients received the allocated intervention. In the treatment group, sublingual microcirculation was not monitored in 2 patients because of prone ventilation or other reasons, and 1 patient discontinued intervention because of an ICU stay of less than 24 hours. In the control group, sublingual microcirculation was not monitored in 2 patients because of prone ventilation or other reasons. Finally, 12 patients in the treatment group and 10 patients in the control group completed the study and were included in the analysis (Fig. 1).

No significant differences were found in sex, age, height, weight, comorbidities, infection sites, disease severity, fluid management, or laboratory parameters between the treatment and control groups (Table 1). Among the included patients, 15 (68.2\%) were male, and the mean age was 57 years. The main comorbidities were hypertension, cerebrovascular disease, diabetes, and coronary heart disease. The main sites of infection were the respiratory system and abdominal cavity. No significant differences were 
found between the treatment and control groups in the length of ICU stay, total hospital stay, or 28-day mortality. No statistically significant differences were found in hemodynamics between the treatment and control groups at baseline, 4 hours and 24 hours after treatment (Table 2). 
Table 1

Characteristics of the enrolled patients

\begin{tabular}{|c|c|c|c|}
\hline Variables & $\begin{array}{l}\text { Overall } \\
(n=22)\end{array}$ & $\begin{array}{l}\text { Control group }(n= \\
10)\end{array}$ & $\begin{array}{l}\text { Treatment group }(n= \\
\text { 12) }\end{array}$ \\
\hline Male, No. (\%) & $15(68.2)$ & $9(90)$ & $6(50)$ \\
\hline Age, years, mean (SD) & $57(18)$ & $59(16)$ & $56(20)$ \\
\hline Height, cm, mean (SD) & $167(7)$ & $171(6)$ & $166(7)$ \\
\hline Weight, kg, mean (SD) & $66(12)$ & $70(12)$ & $63(11)$ \\
\hline \multicolumn{4}{|l|}{ Comorbidity, No. (\%) } \\
\hline Hypertension & $10(45.5)$ & $3(30)$ & $7(58.3)$ \\
\hline Cerebrovascular disease & $7(31.8)$ & $3(30)$ & $4(33.3)$ \\
\hline Diabetes & $4(18.2)$ & $1(10)$ & $3(25)$ \\
\hline Coronary heart disease & $3(13.6)$ & $2(20)$ & $1(8.3)$ \\
\hline \multicolumn{4}{|l|}{ The site of infection, No. (\%) } \\
\hline Respiratory system & $11(50)$ & $5(50)$ & $6(50)$ \\
\hline Abdominal cavity & $10(45.5)$ & $5(50)$ & $5(41.7)$ \\
\hline Urinary system & $1(4.5)$ & $0(0)$ & $1(8.3)$ \\
\hline APACHE II score, mean (SD) & $21.5(5.2)$ & $20.4(6.1)$ & $22.8(3.8)$ \\
\hline SOFA score, mean (SD) & $8.5(2.9)$ & $8.3(2.9)$ & $8.8(2.9)$ \\
\hline $\begin{array}{l}\text { Norepinephrine dose, } \mu \mathrm{g} / \mathrm{min} \text {, median } \\
\text { (IQR) }\end{array}$ & $30(25,53)$ & $33(18,86)$ & $30(25,40)$ \\
\hline \multicolumn{4}{|l|}{ Fluid management } \\
\hline $\begin{array}{l}\text { Fluid intake at first } 24 \text { hours, } \mathrm{mL} \text {, } \\
\text { mean (SD) }\end{array}$ & 4711 (1983) & $4847(2136)$ & $4598(1935)$ \\
\hline $\begin{array}{l}\text { Fluid output at first } 24 \text { hours, mL, } \\
\text { mean (SD) }\end{array}$ & $3531(2085)$ & 3732 (2228) & 3365 (2044) \\
\hline \multicolumn{4}{|l|}{ Laboratory parameters } \\
\hline White blood cells, $\times 10^{9} / \mathrm{L}$, mean (SD) & $15.2(6.6)$ & $15.3(8.1)$ & $15.1(5.5)$ \\
\hline Procalcitonin, ng/mL, median (IQR) & $8.2(2.8,17.5)$ & $8.8(2.9,17.5)$ & $7.3(3.8,14.1)$ \\
\hline
\end{tabular}

APACHE II, Acute Physiology and Chronic Health Evaluation II; APTT, Activated partial thromboplastin time; FDP, Fibrin degradation products; ICU, intensive care unit; IQR, interquartile range; PT, Prothrombin time; SD, standard deviation; SOFA, Sequential Organ Failure Assessment. 


\begin{tabular}{|llll|}
\hline Variables & $\begin{array}{l}\text { Overall } \\
(\mathbf{n = 2 2})\end{array}$ & $\begin{array}{l}\text { Control group }(\mathbf{n}= \\
\mathbf{1 0})\end{array}$ & $\begin{array}{l}\text { Treatment group }(\mathbf{n}= \\
\mathbf{1 2})\end{array}$ \\
\hline C-reactive protein, mg/L, median (IQR) & $163(95,186)$ & $158(85,186)$ & $167(103,180)$ \\
\hline Hemoglobin, g/L, mean (SD) & $106(25)$ & $111(20)$ & $103(29)$ \\
\hline Platelet count, $\times 10^{9} / \mathrm{L}$, median (IQR) & $128(81,241)$ & $139(85,218)$ & $128(70,266)$ \\
\hline PT, S, mean (SD) & $15.2(2.3)$ & $15.6(2.9)$ & $14.8(1.6)$ \\
\hline APPT, S, median (IQR) & $37(33,52)$ & $37(33,40)$ & $36(34,60)$ \\
\hline FDP, $\mu$ g/mL, median (IQR) & $10.4(8.8,16)$ & $9.9(8.7,13.6)$ & $13(9.8,21.7)$ \\
\hline D-Dimer, mg/L, median (IQR) & $\begin{array}{l}1.44 \\
(1.14,2.59)\end{array}$ & $1.21(1.10,3.58)$ & $1.60(1.13,2.30)$ \\
\hline Lactate, mmol/L, median (IQR) & $3(1.7,4.1)$ & $3.2(2.4,5.2)$ & $2.6(1.5,3.8)$ \\
\hline ICU stay, days, median (IQR) & $7(4,17)$ & $11(4,19)$ & $7(5,11)$ \\
\hline Hospital stay, days, median (IQR) & $15(7,21)$ & $17(12,20)$ & $12(6,22)$ \\
\hline 28-day mortality, No. (\%) & $8(36.4)$ & $4(40)$ & $4(33.3)$ \\
\hline $\begin{array}{l}\text { APACHE II, Acute Physiology and Chronic Health Evaluation Il; APTT, Activated partial thromboplastin } \\
\text { time; FDP, Fibrin degradation products; ICU, intensive care unit; IQR, interquartile range; PT, }\end{array}$ \\
\hline Prothrombin time; SD, standard deviation; SOFA, Sequential Organ Failure Assessment.
\end{tabular}


Table 2

Hemodynamic characteristics of the patients

\begin{tabular}{|c|c|c|c|c|}
\hline Variables & Group & Baseline & $\begin{array}{l}4 \text { hours } \\
\text { after treatment }\end{array}$ & $\begin{array}{l}24 \text { hours } \\
\text { after treatment }\end{array}$ \\
\hline \multirow[t]{2}{*}{ Heart rate, bpm, mean (SD) } & Treatment & $106(24)$ & 89 (20)\# & 93 (18)\# \\
\hline & Control & $123(27)$ & $101(15)$ & $102(15)$ \\
\hline \multirow[t]{2}{*}{ CVP, mmHg, mean (SD) } & Treatment & $10(2)$ & $9(3)$ & $8(3) \#$ \\
\hline & Control & $11(3)$ & $11(2)$ & $9(2)$ \\
\hline \multirow[t]{2}{*}{ MAP, mmHg, mean (SD) } & Treatment & $81(10)$ & $83(12)$ & $87(9)$ \\
\hline & Control & $77(12)$ & $84(10)$ & $84(9)$ \\
\hline \multirow[t]{2}{*}{$\mathrm{CO}, \mathrm{L} / \mathrm{min}$, mean (SD) } & Treatment & $6.5(1.6)$ & $6.1(1.2)$ & $6.7(0.7)$ \\
\hline & Control & $6.3(1.1)$ & $6.8(0.6)$ & $6.7(0.8)$ \\
\hline \multirow[t]{2}{*}{ GEDV, mL, mean (SD) } & Treatment & $1355(369)$ & $1349(400)$ & $1304(402)$ \\
\hline & Control & $1255(197)$ & $1182(290)$ & $1240(228)$ \\
\hline \multirow[t]{2}{*}{ SVRI, dyn.s.cm ${ }^{-5} \cdot \mathrm{m}^{2}$, mean (SD) } & Treatment & $1513(366)$ & $1662(498)$ & $1563(454)$ \\
\hline & Control & $1508(283)$ & $1385(388)$ & $1340(297)$ \\
\hline $\begin{array}{l}\text { CO, cardiac output; CVP, central ve } \\
\text { arterial pressure; SD, standard de } \\
\text { baseline, } P<0.05 \text {. }\end{array}$ & $\begin{array}{l}\text { s pressure; } \\
\text { on: SVRI, sy }\end{array}$ & $\begin{array}{l}\text { EDV, global } € \\
\text { temic vascula }\end{array}$ & $\begin{array}{l}\text {-diastolic volume } \\
\text { esistance index. }\end{array}$ & $\begin{array}{l}\text { MAP, mean } \\
\text { ompared with }\end{array}$ \\
\hline
\end{tabular}

\section{Primary Outcome}

We scored the sublingual microcirculation images according to the second consensus on the assessment of sublingual microcirculation, and a score greater than 6 points indicated that image quality was substandard. The sublingual microcirculation image scores included in the final image analysis were fewer than 6 points (Additional file 4). No statistically significant difference was found in the PVD between the treatment and control groups at baseline (mean difference, 2.603; 95\% $\mathrm{Cl},-0.847-6.053 ; \mathrm{P}=$ $0.122)$. The PVD in the treatment group was significantly higher than that in the control group at 4 hours after treatment (mean difference, $7.042 ; 95 \% \mathrm{Cl}, 2.227-11.857 ; \mathrm{P}=0.009$ ) and 24 hours after treatment (mean difference, $7.075 ; 95 \% \mathrm{Cl}, 2.390-11.759 ; \mathrm{P}=0.008$ ) (Fig. 2).

\section{Secondary Outcomes}

No statistically significant differences were found in the PPV, TVD, or MFI between the treatment and control groups at baseline. The PPV (mean difference, 13.490; 95\% Cl, 2.798-24.182; P = 0.019), TVD 
(mean difference, 5.659; 95\% Cl, 1.340-9.979; $\mathrm{P}=0.016$ ), and MFI (mean difference, $0.459 ; 95 \% \mathrm{Cl}$, $0.033-0.885 ; P=0.037$ ) were significantly higher in the treatment group than in the control group at 24 hours after treatment (Fig. 2).

After adjusting for the $\mathrm{Pl}$ and RBF at baseline, we observed that the $\mathrm{PI}$ (mean difference, 8.151;95\% $\mathrm{Cl}$, 2.748-13.553; $\mathrm{P}=0.005$ ) and RBF (mean difference, $9.402 ; 95 \% \mathrm{Cl}, 3.092-15.712 ; \mathrm{P}=0.006$ ) in the treatment group were significantly higher than those in the control group at 24 hours after treatment. No statistically significant differences were found in the RBV, TTP, or MTT at 24 hours after treatment in the treatment group compared with that in the control group (Fig. 3).

After adjusting for the lactate levels at baseline, the lactate levels were significantly lower in the treatment group than in the control group at 24 hours after treatment (mean difference, 2.839; 95\% Cl, 0.280-5.398; $P=0.032$ ) (Fig. 4). No significant differences were found in the norepinephrine dose between the treatment and control groups at baseline, 4 hours and 24 hours after treatment (Additional file 5).

\section{Discussion}

This prospective, double-blind, randomized controlled trial aimed to observe the effects of hydrocortisone combined with vitamin $\mathrm{C}$ and vitamin B1 versus hydrocortisone alone on microcirculation in patients with septic shock. The sublingual microcirculation in the treatment group was significantly better than that in the control group at 24 hours after treatment. It suggests that combination therapy can protect microcirculation. The results were further supported by the protective effect of the combination therapy on renal perfusion monitored by renal CEUS.

Septic shock is associated with microthrombosis, impaired endothelial barrier function, microvascular abnormalities, and mitochondrial dysfunction [19-21]. Hydrocortisone combined with vitamin $C$ and vitamin B1 protects endothelial function and improves microcirculation through multiple pathways ${ }^{[15]}$. First, the antioxidant effect of vitamin $\mathrm{C}$ can reduce the permeability of endothelial cells, protect the function of microcirculation and reduce apoptosis by maintaining endothelial integrity [22-24]. Second, vitamin $\mathrm{C}$ has an immunomodulatory function, which reduces the production of inflammatory mediators and regulates the function of macrophages $[25,26]$. Third, vitamin $C$ plays an important role in the generation of vasopressors and maintaining vasopressor responsiveness [27]. Fourth, vitamin B1 is a key component of cell metabolism and can improve mitochondrial function, increase lactate clearance and protect organ function $[28,29]$. However, vitamin $C$ and vitamin B1 deficiency is common in septic shock patients and is associated with a poor prognosis [28, 30,31]. Therefore, supplementation with vitamin $C$ and vitamin B1 in septic shock patients protects endothelial barrier function and improves microcirculation.

Hydrocortisone and vitamin $\mathrm{C}$ have synergistic effects on protecting endothelial barrier function and microcirculation. First, oxygen-free radicals reduce the activity of glucocorticoid receptors, and vitamin $\mathrm{C}$ may protect and restore glucocorticoid receptor function. Second, vitamin $\mathrm{C}$ uptake by cells is mediated 
by the sodium-vitamin C transporter 2 (SVCT2). However, SVCT2 is downregulated in septic shock, and glucocorticoids increase the expression of SVCT2 [16,32]. Thus, the combination of hydrocortisone and vitamin $\mathrm{C}$ can improve their physiological effects on protecting endothelial cells and microcirculation.

Current studies have drawn inconsistent conclusions $[5-10,13,14,33]$. In the VITAMINS study, the combination therapy did not reduce the 90-day mortality but reduced the SOFA score at day 3 in septic shock patients [11]. In the ACTS trial, the combination therapy did not result in a statistically significant reduction in the SOFA score during the first 72 hours after enrollment and the 30-day mortality [12]. However, the subsequent meta-analysis showed that vitamin $\mathrm{C}$ alone or in combination with hydrocortisone/thiamine (treatment 3 to 4 days) reduces the 30-day mortality in patients with septic shock [5]. The heterogeneity of these results may be related to the differences in the efficacy of the combination therapy for different septic shock subtypes. A retrospective cohort study explored the effects of combination therapy on different septic shock subtypes and found that clinical outcomes may be better for patients with hyperinflammatory subtypes [34]. Additionally, procalcitonin may be an effective biomarker for monitoring the efficacy of the combination therapy [35]. Our study supports using combination therapy in septic patients because of its protective effect on microcirculation.

This study has some strengths. First, it used a prospective randomized controlled study design to ensure patient comparability between the treatment and control groups. We concealed the randomized results to avoid patient selection bias. Second, two researchers independently analyzed the microcirculation images, and we blinded microcirculation evaluators to the grouping scheme. We scored all microcirculation images to evaluate image quality and eliminated substandard images. Third, we performed bedside monitoring of renal perfusion using renal CEUS and compared the effects of different treatments on renal perfusion to support the primary outcome.

The limitations of this study were as follows. First, this was a single-center study with small sample size, characteristics that could affect the generality of the findings. Second, our grouping scheme did not blind clinicians. Each patient was comanaged by at least three clinicians, and no conflict of interest was found between the clinicians and the study. Third, we did not consider other vasoactive agent doses (epinephrine, dopamine, and vasopressin) when comparing the effects of different treatments on norepinephrine doses. Of the 22 patients included in the analysis, only one in the control group received epinephrine 24 hours after treatment. Fourth, according to the study design, the duration of the three drugs was 24 hours. It makes this study insufficient to evaluate the effects of the combination therapy on clinical outcomes, such as ICU mortality. Fifth, we did not monitor the plasma vitamin C and vitamin B1 levels.

\section{Conclusion}

Compared with hydrocortisone alone, the combination therapy significantly improved microcirculation in septic shock patients. This finding is further supported by improved renal perfusion in the treatment group. This study supports the supplementation of hydrocortisone, vitamin C, and vitamin B1 in septic 
shock patients. Large randomized controlled trials are needed to explore the effect of the combination therapy on outcome in septic shock patients and determine which subgroup of septic shock is more likely to respond to the combination therapy.

\section{List Of Abbreviations}

CEUS, contrast-enhanced ultrasound; ICU, intensive care unit; MAP, mean arterial pressure; MFI, microvascular flow index; MTT, mean transfer time; PI, peak intensity; PPV, proportion of perfusion vessels; PVD, perfusion vascular density; RBF, regional blood flow; RBV, regional blood volume; SOFA, sequential organ failure assessment; SVCT2, sodium-vitamin C transporter 2; TTP, time to peak; TVD, total vascular density.

\section{Declarations}

\section{Ethics approval and consent to participate}

The Clinical Research Ethics Committee of the Zhongda Hospital affiliated with Southeast University approved this study (2018ZDSYLL057-P01), and all participants signed informed consent forms.

\section{Consent for publication}

Not applicable.

\section{Availability of data and materials}

The datasets used and analysed during the current study are available from the corresponding author on reasonable request.

\section{Competing interests}

The authors declare that they have no competing interests.

\section{Funding}

The National Natural Science Foundation of China (81971812), the Natural Science Foundation of Jiangsu Province (BK20191264 and BK20200367), and the Science Foundation of the Commission of Health of Jiangsu Province (ZDB2020009) supported this study.

\section{Authors' contributions}

JLW, LLH, QL, JYX, JFX, and YZH contributed to the conception of the study; JLW, QWS, SHY, HFW, and SSM contributed to data collection; JLW, QWS, SHY, HFW, and YZH contributed to data analysis and interpretation; JLW drafted the manuscript; and JLW, QWS, SHY, HFW, SSM, LLH, QL, JYX, JFX, and YZH revised the manuscript. All authors read and approved the final manuscript. 
Acknowledgements

We sincerely thank all patients who participated in this study. We thank Bingjie Yang and Xiaoling Lu (Department of Ultrasound Medicine, Zhongda Hospital, School of Medicine, Southeast University) for helping us performed the renal contrast-enhanced ultrasound.

\section{References}

1. Rudd KE, Johnson SC, Agesa KM, Shackelford KA, Tsoi D, Kievlan DR, et al. Global, regional, and national sepsis incidence and mortality, 1990-2017: analysis for the Global Burden of Disease Study. Lancet. 2020;395:200-1.

2. Xie J, Wang H, Kang Y, Zhou L, Liu Z, Qin B, et al. The Epidemiology of Sepsis in Chinese ICUs: A National Cross-Sectional Survey. Crit Care Med. 2020;48:e209-18.

3. Marik PE, Khangoora V, Rivera R, Hooper MH, Catravas J. Hydrocortisone. Vitamin C, and Thiamine for the Treatment of Severe Sepsis and Septic Shock: A Retrospective Before-After Study. Chest. 2017;151:1229-38.

4. Vail EA, Wunsch H, Pinto R, Bosch NA, Walkey AJ, Lindenauer PK, et al. Use of Hydrocortisone, Ascorbic Acid, and Thiamine in Adults with Septic Shock. Am J Respir Crit Care Med. 2020;202:1531-9.

5. Scholz SS, Borgstedt R, Ebeling N, Menzel LC, Jansen G, Rehberg S. Mortality in septic patients treated with vitamin C: a systematic meta-analysis. Crit Care. 2021;25:17.

6. Wani SJ, Mufti SA, Jan RA, Shah SU, Qadri SM, Khan UH, et al. Combination of vitamin C, thiamine and hydrocortisone added to standard treatment in the management of sepsis: results from an open label randomised controlled clinical trial and a review of the literature. Infect Dis (Lond). 2020;52:271-8.

7. Sadaka F, Grady J, Organti N, Donepudi B, Korobey M, Tannehill D, et al. Ascorbic Acid, Thiamine, and Steroids in Septic Shock: Propensity Matched Analysis. J Intensive Care Med. 2020;35:1302-6.

8. Mitchell AB, Ryan TE, Gillion AR, Wells LD, Muthiah MP. Vitamin C and Thiamine for Sepsis and Septic Shock. Am J Med. 2020;133:635-8.

9. Chang P, Liao Y, Guan J, Guo Y, Zhao M, Hu J, et al. Combined Treatment With Hydrocortisone, Vitamin C, and Thiamine for Sepsis and Septic Shock: A Randomized Controlled Trial. Chest. 2020;158:174-82.

10. Coloretti I, Biagioni E, Venturelli S, Munari E, Tosi M, Roat E, et al. Adjunctive therapy with vitamin $C$ and thiamine in patients treated with steroids for refractory septic shock: A propensity matched before-after, case-control study. J Crit Care. 2020;59:37-41.

11. Fujii T, Luethi N, Young PJ, Frei DR, Eastwood GM, French CJ, et al. Effect of Vitamin C, Hydrocortisone, and Thiamine vs Hydrocortisone Alone on Time Alive and Free of Vasopressor Support Among Patients With Septic Shock: The VITAMINS Randomized Clinical Trial. JAMA. 2020;323:423-31. 
12. Moskowitz A, Huang DT, Hou PC, Gong J, Doshi PB, Grossestreuer AV, et al. Effect of Ascorbic Acid, Corticosteroids, and Thiamine on Organ Injury in Septic Shock: The ACTS Randomized Clinical Trial. JAMA. 2020;324:642-50.

13. Litwak JJ, Cho N, Nguyen HB, Moussavi K, Bushell T. Vitamin C. Hydrocortisone, and Thiamine for the Treatment of Severe Sepsis and Septic Shock: A Retrospective Analysis of Real-World Application. J Clin Med. 2019;8.

14. Chang K, Harbin M, Shuster C, Griesdale DEG, Foster D, Sweet D, et al. Adding vitamin $C$ to hydrocortisone lacks benefit in septic shock: a historical cohort study. Can J Anaesth. 2020;67:1798-805.

15. Marik PE. Vitamin C for the treatment of sepsis: The scientific rationale. Pharmacol Ther. 2018;189:63-70.

16. Barabutis N, Khangoora V, Marik PE, Catravas JD. Hydrocortisone and Ascorbic Acid Synergistically Prevent and Repair Lipopolysaccharide-Induced Pulmonary Endothelial Barrier Dysfunction. Chest. 2017;152:954-62.

17. Singer M, Deutschman CS, Seymour CW, Shankar-Hari M, Annane D, Bauer M, et al. The Third International Consensus Definitions for Sepsis and Septic Shock (Sepsis-3). JAMA. 2016;315:80110.

18. Rhodes A, Evans LE, Alhazzani W, Levy MM, Antonelli M, Ferrer R, et al. Surviving Sepsis Campaign: International Guidelines for Management of Sepsis and Septic Shock: 2016. Intensive care medicine. 2017;43:304-77.

19. Angus DC, van der Poll T. Severe sepsis and septic shock. N Engl J Med. 2013;369:840-51.

20. Lelubre C, Vincent JL. Mechanisms and treatment of organ failure in sepsis. Nat Rev Nephrol. 2018;14:417-27.

21. Brealey D, Brand M, Hargreaves I, Heales S, Land J, Smolenski R, et al. Association between mitochondrial dysfunction and severity and outcome of septic shock. Lancet. 2002;360:219-23.

22. Oudemans-van Straaten HM, Spoelstra-de Man AM, de Waard MC. Vitamin C revisited. Crit Care. 2014;18:460.

23. Amrein K, Oudemans-van Straaten HM, Berger MM. Vitamin therapy in critically ill patients: focus on thiamine, vitamin C, and vitamin D. Intensive care medicine. 2018;44:1940-4.

24. Moskowitz A, Andersen LW, Huang DT, Berg KM, Grossestreuer AV, Marik PE, et al. Ascorbic acid, corticosteroids, and thiamine in sepsis: a review of the biologic rationale and the present state of clinical evaluation. Crit Care. 2018;22:283.

25. Victor VV, Guayerbas N, Puerto M, Medina S, De la Fuente M. Ascorbic acid modulates in vitro the function of macrophages from mice with endotoxic shock. Immunopharmacology. 2000;46:89-101.

26. Cárcamo JM, Pedraza A, Bórquez-Ojeda O, Golde DW. Vitamin C suppresses TNF alpha-induced NF kappa B activation by inhibiting I kappa B alpha phosphorylation. Biochemistry. 2002;41:129953002. 
27. Carr AC, Shaw GM, Fowler AA, Natarajan R. Ascorbate-dependent vasopressor synthesis: a rationale for vitamin C administration in severe sepsis and septic shock? Crit Care. 2015;19:418.

28. Donnino MW, Andersen LW, Chase M, Berg KM, Tidswell M, Giberson T, et al. Randomized, DoubleBlind, Placebo-Controlled Trial of Thiamine as a Metabolic Resuscitator in Septic Shock: A Pilot Study. Crit Care Med. 2016;44:360-7.

29. Ikeda K, Liu X, Kida K, Marutani E, Hirai S, Sakaguchi M, et al. Thiamine as a neuroprotective agent after cardiac arrest. Resuscitation. 2016;105:138-44.

30. Mallat J, Lemyze M, Thevenin D. Do not forget to give thiamine to your septic shock patient! J Thorac Dis. 2016;8:1062-6.

31. Carr AC, Rosengrave PC, Bayer S, Chambers S, Mehrtens J, Shaw GM. Hypovitaminosis C and vitamin $\mathrm{C}$ deficiency in critically ill patients despite recommended enteral and parenteral intakes. Crit Care. 2017;21:300.

32. Fujita I, Hirano J, Itoh N, Nakanishi T, Tanaka K. Dexamethasone induces sodium-dependant vitamin C transporter in a mouse osteoblastic cell line MC3T3-E1. Br J Nutr. 2001;86:145-9.

33. Iglesias J, Vassallo AV, Patel VV, Sullivan JB, Cavanaugh J, Elbaga Y. Outcomes of Metabolic Resuscitation Using Ascorbic Acid, Thiamine, and Glucocorticoids in the Early Treatment of Sepsis: The ORANGES Trial. Chest. 2020;158:164-73.

34. Kim WY, Jung JW, Choi JC, Shin JW, Kim JY. Subphenotypes in Patients with Septic Shock Receiving Vitamin C, Hydrocortisone, and Thiamine: A Retrospective Cohort Analysis. Nutrients. 2019;11.

35. Marik PE. Procalcitonin is an essential biomarker for hydrocortisone, ascorbic acid, and thiamine (HAT) therapy in patients with sepsis. Crit Care. 2019;23:151.

\section{Figures}




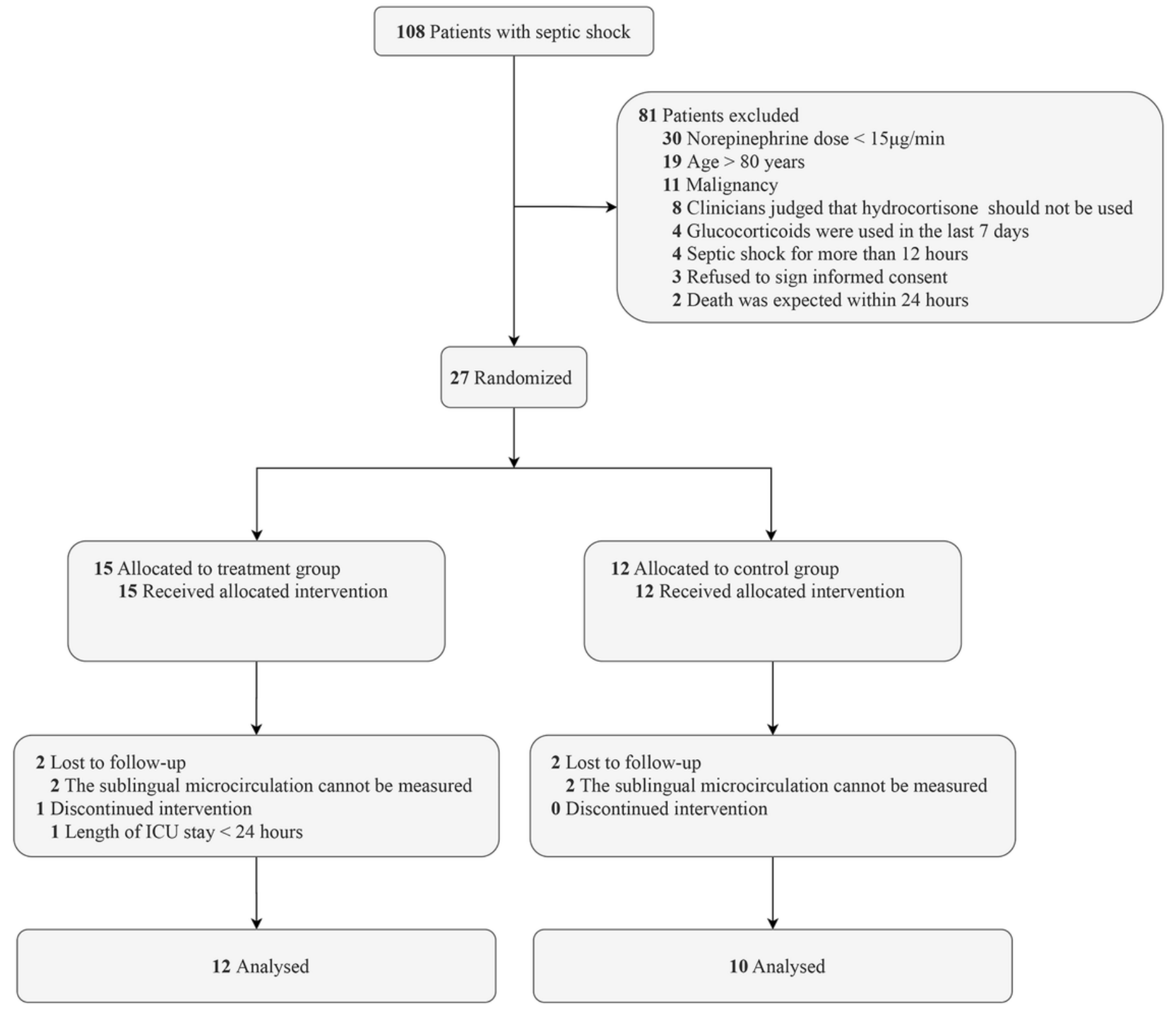

Figure 1

Flow diagram. 

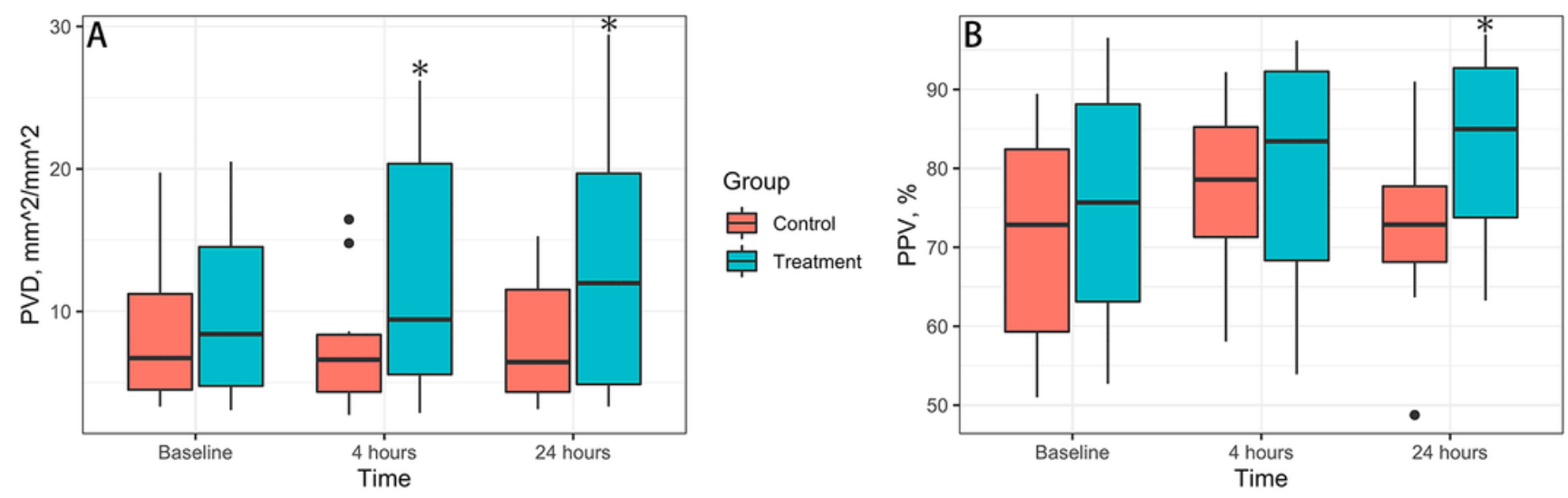

Group

官 Control

官 Treatment
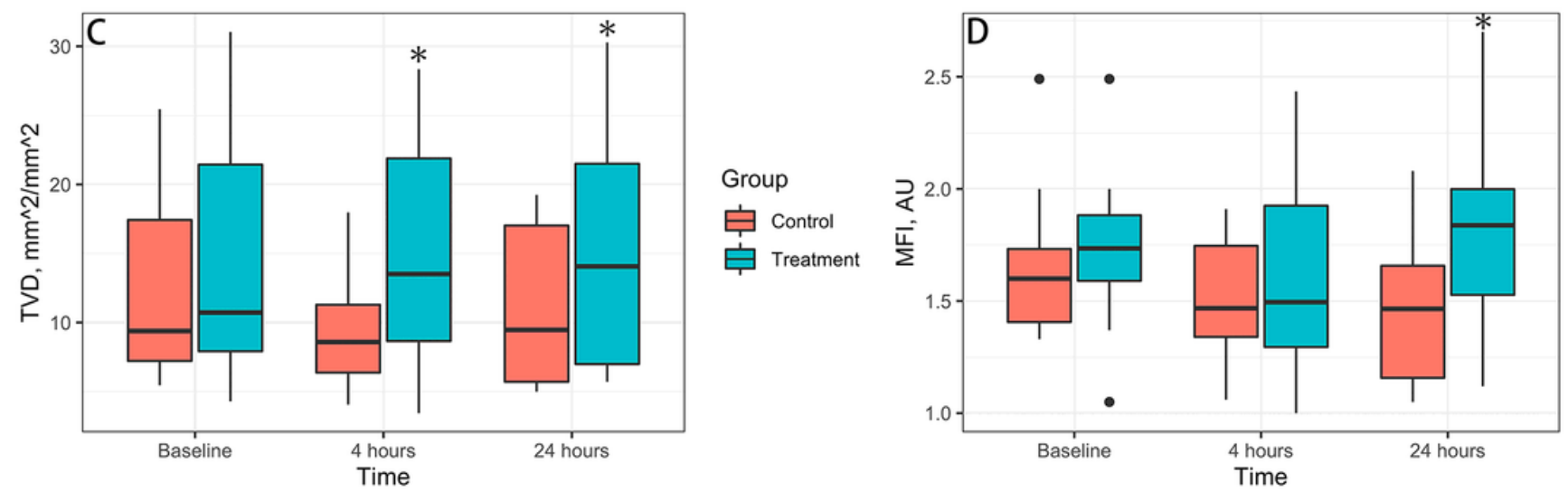

Group

它 Control

官 Treatment

Figure 2

Effects of hydrocortisone combined with vitamin $C$ and vitamin B1 versus hydrocortisone alone on microcirculation in septic shock patients. A shows the effect on PVD. B shows the effect on PPV. C shows the effect on TVD. D shows the effect on MFI. PVD, Perfusion vessel density; PPV, Proportion of perfusion vessels; TVD, Total vascular density; MFI, Microvascular flow index. Boxplot indicates median (interquartile range) with maximum and minimum values. ${ }^{*}$ Compared with the control group, $\mathrm{P}<0.05$. 

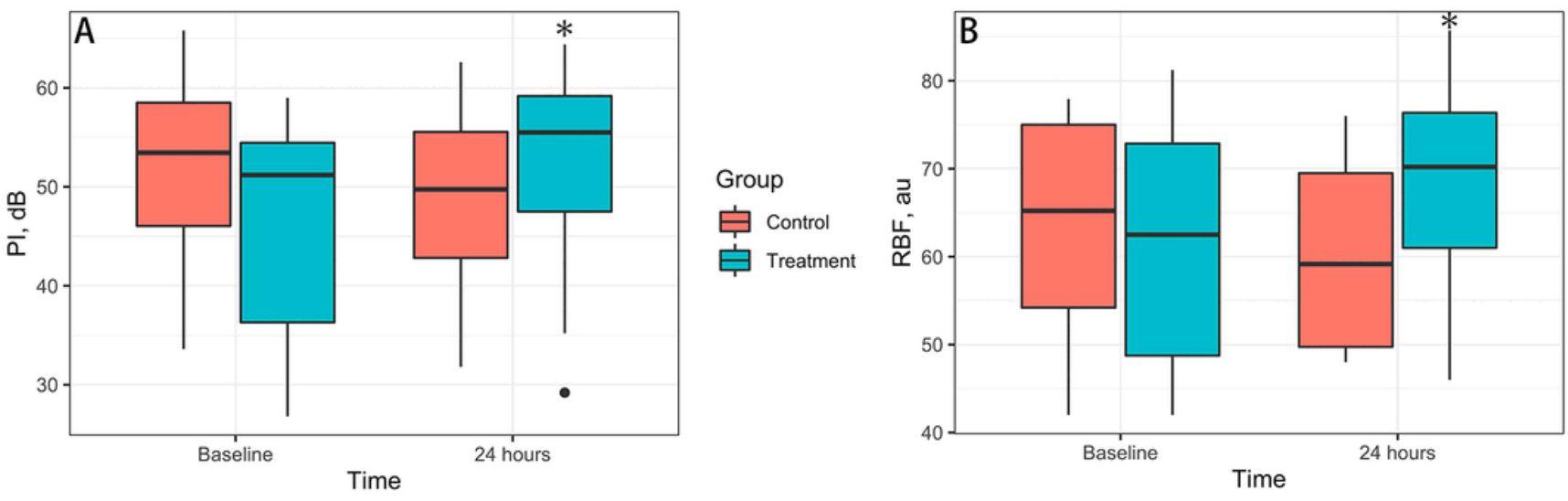

Group

它 Control

官 Treatment
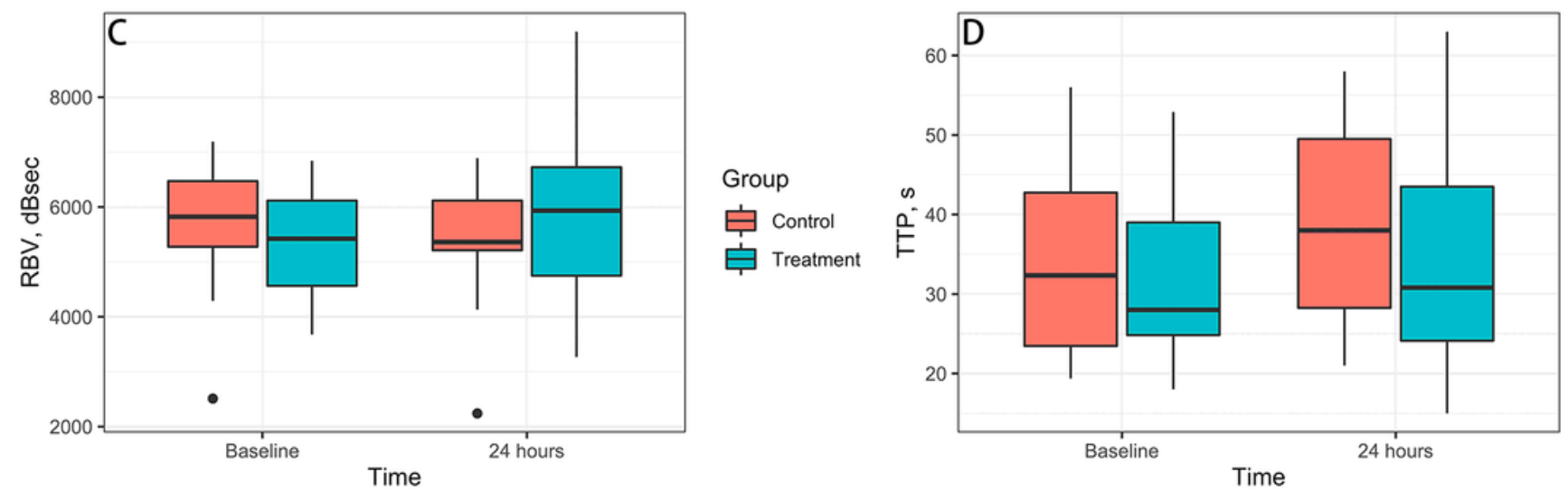

Group
官 Control
官 Treatment

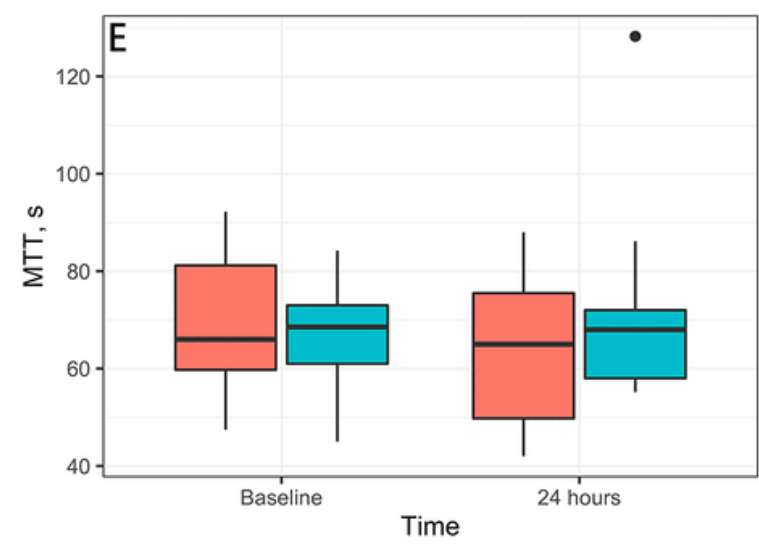

Group

官 Control

审 Treatment

Figure 3

Effects of hydrocortisone combined with vitamin $\mathrm{C}$ and Vitamin B1 versus hydrocortisone alone on renal perfusion in septic shock patients. A shows the effect on PI. B shows the effect on RBF. C shows the effect on RBV. D shows the effect on TTP. E shows the effect on MTT. MTT, mean transfer time; PI, peak intensity; RBF, regional blood flow; RBV, region blood volume; TTP, time to peak. Boxplot indicates median (interquartile range) with maximum and minimum values. ${ }^{*}$ Compared with the control group, $P<0.05$. 


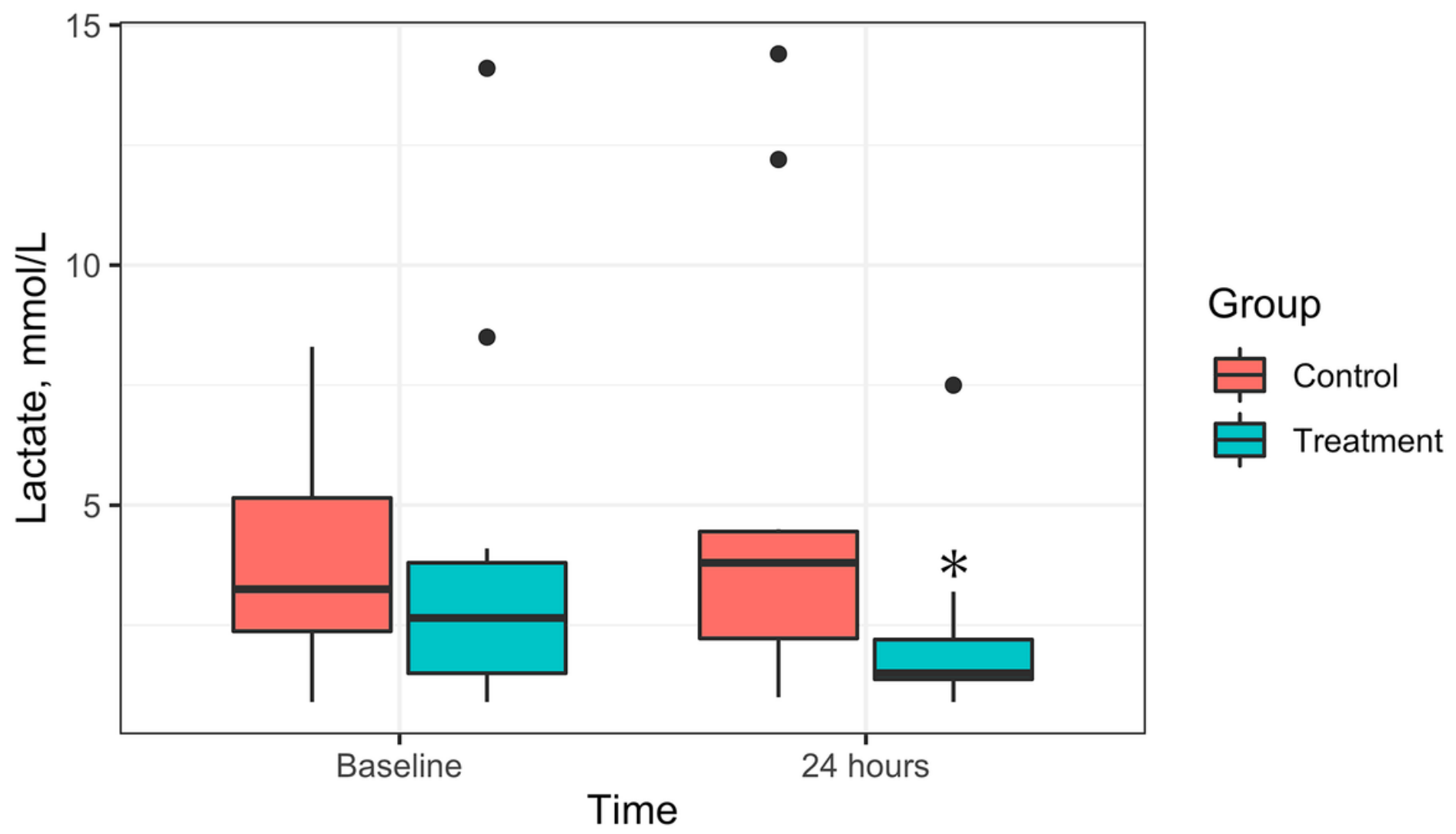

Figure 4

Effect of hydrocortisone combined with vitamin C and Vitamin B1 versus hydrocortisone alone on lactate in septic shock patients. Boxplot indicates median (interquartile range) with maximum and minimum values. ${ }^{*}$ Compared with the control group, $\mathrm{P}<0.05$.

\section{Supplementary Files}

This is a list of supplementary files associated with this preprint. Click to download.

- Additionalfile.docx 